GRANADO, Emerson Rodrigo Araújo. ZANON JUNIOR, Orlando Luiz. SANTOS, Rafael Padilha dos. A argumentação jurídica como instrumento de articulação das razões de justificação da decisão judicial. Revista Eletrônica Direito e Política, Programa de Pós-Graduação Stricto Sensu em Ciência Jurídica da UNIVALI, Itajaí, v.11, n.1, 10 quadrimestre de 2016. Disponível em: www.univali.br/direitoepolitica - ISSN 1980-7791.

\title{
A ARGUMENTAÇÃO JURÍDICA COMO INSTRUMENTO DE ARTICULAÇÃO DAS RAZÕES DE JUSTIFICAÇÃO DA DECISÃO JUDICIAL
}

\author{
THE LEGAL REASONING AS ARTICULATION INSTRUMENT OF THE REASONS TO \\ DECISION JUSTIFICATION
}

\author{
Emerson Rodrigo Araújo Granado' \\ Orlando Luiz Zanon Junior ${ }^{2}$ \\ Rafael Padilha dos Santos ${ }^{3}$
}

SUMÁRIO: Introdução; 1. Evolução histórica da teoria da argumentação jurídica; 2. O caráter prescritivo da ciência jurídica e a contribuição da argumentação jurídica no seu desenvolvimento; 3. A argumentação jurídica como instrumento de articulação das razões de justificação da decisão judicial; Considerações Finais; Referência das Fontes Citadas.

\section{RESUMO}

O presente artigo científico se propõe, de modo coeso, a analisar a teoria da argumentação jurídica em seu processo evolutivo, desde a construção do pensamento crítico de Theodor Viehweg, da retomada da retórica aristotélica em Perelman, a construção das teorias argumentativas-discursivas, pautadas na teoria do discurso de Habermas. O objeto da presente pesquisa é analisar a contribuição da teoria da argumentação jurídica como instrumento de articulação das razões de justificação da decisão judicial. Para alcançar tal enfoque, a pesquisa será dividida em três momentos. No primeiro se fará um escorço historiográfico da teoria da argumentação jurídica. $\mathrm{Na}$ segunda etapa, estudar-se-á o caráter prescritivo da ciência jurídica e a contribuição da argumentação jurídica no seu desenvolvimento. Por fim, no terceiro momento, dedicarse-á à apreciação da argumentação jurídica como instrumento de articulação das razões de justificação da decisão judicial. Utilizou-se, para o desenvolvimento desta presente pesquisa, o método indutivo, operacionalizados pelas técnicas de conceitos operacionais e da pesquisa bibliográfica.

\footnotetext{
${ }^{1}$ Mestrando em Ciência Jurídica pela UNIVALI. Advogado. Especialista em Direito Notarial e Registral. Taxista do PROSUP - CAPES. Bacharel pelo Curso de Direito da Universidade do Vale do Itajaí. E-mail: emersonrodrigo@granado.adv.br

2 Juiz de Direito. Doutor em Ciência Jurídica pela UNIVALI. Dupla titulação em Doutorado pela UNIPG (Itália). Mestre em Direito Pela UNESA. Pós-graduado pela UNIVALI e pela UFSC. Professor da Escola da Magistratura de Santa Catarina (ESMESC), da Acadêmia Judicial (AJ) e do Programa de Pós-graduação da UNIVALI. Membro da Academia Catarinense de Letra Jurídicas (ACALEJ).

${ }^{3}$ O autor é Doutor em dupla titulação pela UNIVALI (Brasil) e pela Universitàdegli Studi di Perugia (Itália). Mestre em Filosofia pela UFSC. Especialização em psicologia social pela Universidade Estatal de São Petersburgo (Rússia). Professor no Programa de PósGraduação Stricto Sensu em Ciência Jurídica, nos cursos de Doutorado e Mestrado em Ciência Jurídica, e na Graduação no Curso de Direito da Universidade do Vale do Itajaí UNIVALI. É Professor do curso de Direito da UNIVALI e advogado. E-mail: rpadilhas@univali.br.
} 
GRANADO, Emerson Rodrigo Araújo. ZANON JUNIOR, Orlando Luiz. SANTOS, Rafael Padilha dos. A argumentação jurídica como instrumento de articulação das razões de justificação da decisão judicial. Revista Eletrônica Direito e Política, Programa de Pós-Graduação Stricto Sensu em Ciência Jurídica da UNIVALI, Itajaí, v.11, n.1, 10 quadrimestre de 2016. Disponível em: www.univali.br/direitoepolitica - ISSN 1980-7791.

PALAVRAS-CHAVE: Teoria da argumentação jurídica; decisão judicial; fontes do direito.

\section{ABSTRACT}

Following cientific article proposes itself, in a cohesive manner, to analise the legal argumentations in its evolutional process, since the construction of Theodor Viehweg's critical thinking, from the resumption of Aristotle's rhetoric by Parelman, to the construction of discursive-argumentative theories, based on Habermas's Discourse theory. The purpose of the ensuing research is to analyse the contribution of the legal reasoning theory, as a tool concerning articulation of approval on grounds of court decision. To reach such a focus, the essay will be divided into three moments. Firtly there will be a historiographic outline of the legal Discourse theory. Secondly, there will be a study on the prescriptive character of legal science and a contribution of legal argumentation in its development. Lastly, on a third moment, there will be an adherence to the appreciation of legal arguments, as a tool concerning articulation of approval on grounds of court decision. For the development of this present research, the inductive method was used, managed by techniques of operational concepts and bibliographic research.

Keywords: Legal reasoning theory, court decision, sources of law.

\section{INTRODUÇÃO}

A ciência jurídica, como produto artificial, tem passado ao longo da história por profundas transformações, no ímpeto de fornecer respostas adequadas aos anseios sociais.

Neste processo de transformação, a ciência jurídica foi marcada pela fixação paradigmática de modelos científicos, os quais serviram de base teórica para o seu desenvolvimento.

No entanto, se percebe que, em determinado momento histórico, ocorre uma ruptura no modelo teórico, por não mais atender as expectativas da comunidade científica.

Especificamente, a ciência jurídica passou pela superação do modelo teórico do jusnaturalismo para o padrão do positivismo jurídico, o qual, por sua vez, encontra-se em momento de profunda crise, caminhando para a construção de um novo horizonte.

Neste contexto, as teorias da argumentação jurídica surgem como proposta crítica ao modelo teórico predominante, transpassando, atualmente, de teoria crítica para a fixação de um novo paradigma, com enfoque na teoria da decisão judicial.

A teoria da argumentação jurídica busca introduzir no discurso jurídico argumentos outros além do texto legal positivado, fixando procedimentos que assegurem a racionalidade na 
GRANADO, Emerson Rodrigo Araújo. ZANON JUNIOR, Orlando Luiz. SANTOS, Rafael Padilha dos. A argumentação jurídica como instrumento de articulação das razões de justificação da decisão judicial. Revista Eletrônica Direito e Política, Programa de Pós-Graduação Stricto Sensu em Ciência Jurídica da UNIVALI, Itajaí, v.11, n.1, 1o quadrimestre de 2016. Disponível em: www.univali.br/direitoepolitica - ISSN 1980-7791.

conclusão do resultado em uma decisão judicial.

Assim, a presente pesquisa analisará a contribuição das teorias da argumentação jurídica na articulação das razões de justificação da decisão judicial.

Portanto, o objeto da presente pesquisa é análise das teorias da argumentação jurídica. O objetivo geral é compreender como teorias da argumentação jurídica podem contribuir como instrumento de articulação das razões de justificação da decisão judicial. Os objetivos específicos são: a) traçar a construção evolutiva da teoria da argumentação jurídica; b) compreender a contribuição das teorias da argumentação jurídica no aspecto prescritivo da ciência jurídica; c) investigar como se desenvolve a argumentação jurídica na articulação das razões de justificação.

O artigo está dividido em três momentos: no primeiro, é delineado um breve retrospecto sobre a evolução histórica da teoria da argumentação jurídica; no segundo, são traçadas considerações acerca do caráter prescritivo da ciência jurídica e sua relação com as bases teóricas voltadas à argumentação; e, no terceiro, trata-se da argumentação jurídica como instrumento de articulação das razões de justificação da decisão judicial.

Quanto à Metodologia, foi utilizado o método Indutivo e, no relatório final, empregadas as técnicas do referente, da categoria, dos conceitos operacionais e da pesquisa bibliográfica ${ }^{4}$.

\section{EVOLUÇÃO HISTÓRICA DA TEORIA DA ARGUMENTAÇÃO JURÍDICA}

Preliminarmente, em aspectos gerais, importa elucidar a teoria da argumentação jurídica através da sua construção histórica, desvendando seu surgimento e as etapas de rupturas e, também, de transpasse entre a teoria crítica e a construção de um novo paradigma jurídico.

O conhecimento científico vem galgando, desde longa data, concepções teóricas que se firmam, através do quase consenso, em paradigmas científicos, que funcionam de base

\footnotetext{
4 "[...] pesquisar e identificar as partes de um fenômeno e colecioná-las de modo a ter uma percepção ou conclusão geral [...]". PASOLD, Cesar Luis. Metodologia da pesquisa jurídica: Teoria e prática. 11 ed. Florianópolis: Conceito editorial/Milleniuum, 2008. p. 86.
} 
GRANADO, Emerson Rodrigo Araújo. ZANON JUNIOR, Orlando Luiz. SANTOS, Rafael Padilha dos. A argumentação jurídica como instrumento de articulação das razões de justificação da decisão judicial. Revista Eletrônica Direito e Política, Programa de Pós-Graduação Stricto Sensu em Ciência Jurídica da UNIVALI, Itajaí, v.11, n.1, 10 quadrimestre de 2016. Disponível em: www.univali.br/direitoepolitica - ISSN 1980-7791.

teórica para o desenvolvimento da comunidade científica em determinada área do saber, conforme a estrutura das revoluções científicas desenvolvida por Thomas S. Kuhn5.

Tal compreensão não passa ao largo da Ciência Jurídica, que caminha ao longo da história com base em modelos teóricos paradigmáticos específicos.

Historicamente, verifica-se que a Ciência Jurídica foi regida por dois grandes paradigmas, a saber: o Jusnaturalismo e, depois, o Positivismo Jurídico. O deles foi firmado sobre a existência de um direito natural, distinto do direito posto, de ordem anterior e superior ${ }^{6}$, isto é, sobre a existência de “(...) uma ordem jurídica universalmente válida, historicamente invariável e axiologicamente superior àquela produzida pelo Estado (...)"7. De outro lado, o segundo, de maneira simplificadora, funda-se no caráter científico, no uso da lógica formal (subsunção), na pretensão de completude, na pureza científica, na racionalidade da lei e na neutralidade do intérprete ${ }^{8}$.

A ruptura paradigmática do jusnaturalismo ao positivismo foi impulsionada pelos movimentos sociais e políticos que tomaram forma na Europa durante os séculos XVIII e $\mathrm{XIX}$

O fortalecimento dos aparelhos estatais nas sociedades capitalistas e a expansão do Estado Liberal, tomados pelos ideais de igualdade formal e de segurança jurídica como valores de justiça, criam um campo fértil para o estabelecimento do positivismo jurídico.

Hodiernamente, o positivismo jurídico é entendido como "uma teoria explicativa do fenômeno jurídico", a qual teve como primeiros representantes, na esfera do civil law, os juristas franceses da escola exegese, seguidos pelo movimento da escola histórica do direito na Alemanha. No âmbito do common law, firmou-se pelos comentários de Bentham e Austin?.

\footnotetext{
${ }^{5}$ Apud ZANON JR., Orlando Luiz. Teoria complexa do direito. Curitiba: Editora Prismas, 2015. p. 40.

${ }^{6}$ FERNÁNDEZ, Eusebio. ASÍS, Rafael de. Curso de teoria del derecho. Madrid: Marcial Pons, 2000. p. 296-300.

7 ZANON JR., Orlando Luiz. Teoria complexa do direito. p. 65.

8 BARROSO, Luís Roberto. Interpretação e aplicação da constituição. São Paulo: Saraiva, 2004. p. 313.

9 DIMOULIS, Dimitri. Positivismo jurídico: Introdução a uma teoria do direito e
} 
GRANADO, Emerson Rodrigo Araújo. ZANON JUNIOR, Orlando Luiz. SANTOS, Rafael Padilha dos. A argumentação jurídica como instrumento de articulação das razões de justificação da decisão judicial. Revista Eletrônica Direito e Política, Programa de Pós-Graduação Stricto Sensu em Ciência Jurídica da UNIVALI, Itajaí, v.11, n.1, 10 quadrimestre de 2016. Disponível em: www.univali.br/direitoepolitica - ISSN 1980-7791.

No entanto, o positivismo jurídico se solidifica de maneira decisiva na teoria normativista de Hans Kelsen, para quem a elevação do direito à condição de ciência dependeria da expurgação de proposições de justiça, ética, de perfil sociológico etc.

O modelo teórico do sistema jurídico proposto por Kelsen seria "unitário, orgânico, fechado, completo e autossuficiente; nele, nada falta para o seu aperfeiçoamento; normas hierarquicamente inferiores buscam seu fundamento de validade em normas hierarquicamente superiores", de sorte que a possibilidade de "abertura para fatores extrajurídicos comprometeria sua rigidez e completude"10.

Percebe-se, desta forma, que o jurista do círculo de Viena buscou a pureza da ciência jurídica mediante o afastamento de qualquer razão de justificação valorativa. Portanto, não caberia aos juristas a valoração do conteúdo da norma posta, porquanto certamente se prefere o direito moral ao imoral, porém não seria isso que retiraria a validade da norma ${ }^{11}$.

Como afirma Mario Losano apud Bittar e Almeida, o traço marcante dessa teoria está na pureza metodológica perseguida por Kelsen através da ausência de juízos de valor ${ }^{12}$.

Ocorre que a pureza metodológica de Kelsen, firmada sobre a epistemologia clássica, começa a entrar em crise, impulsionada no período pós-guerra, "marcado por um sentimento de insatisfação com todas as teses jurídicas que reduziam o papel do jurista prático à ‘aplicação' de um direito inteiramente moldado pelo legislador”13.

Nesta toada, o distanciamento dos valores sociais do direito, em face da completa ausência do juízo valorativo do conteúdo do texto legal, instaura uma verdadeira crise de legitimidade do discurso jurídico, em especial na decisão judicial, que ecoa na construção

defesa do pragmatismo jurídico-político. São Paulo: Método, 2006. p. 66-71.

10 BITTAR, Eduardo C. B.; ALMEIRA, Guilherme Assis de. Curso de filosofia do direito. São Paulo: Atlas, 2015. p. 434-435.

${ }^{11}$ KELSEN, Hans. Teoria pura do direito. Trad. João Baptista Machado. Coimbra: Arménio Amado. 1976. p. 100.

12 BITTAR, Eduardo C. B.; ALMEIRA, Guilherme Assis de. Curso de filosofia do direito. p. 432.

13 BUSTAMANTE, Thomas da Rosa de. Tópica e argumentação jurídica.In: Revista de informação legislativa, v. 41, n. 163, p. 153-165, jul./set. 2004. Disponível em http://www2.senado.leg.br/bdsf/item/id/985. Acesso em 13/02/2016. 
GRANADO, Emerson Rodrigo Araújo. ZANON JUNIOR, Orlando Luiz. SANTOS, Rafael Padilha dos. A argumentação jurídica como instrumento de articulação das razões de justificação da decisão judicial. Revista Eletrônica Direito e Política, Programa de Pós-Graduação Stricto Sensu em Ciência Jurídica da UNIVALI, Itajaí, v.11, n.1, 10 quadrimestre de 2016. Disponível em: www.univali.br/direitoepolitica - ISSN 1980-7791.

de teorias críticas do direito.

Segundo Barroso, "uma das teses fundamentais do pensamento crítico é a admissão de que o Direito possa não estar integralmente contido na lei, tendo condição de existir independentemente da benção estatal, da positivação (...)"14.

A descrença na completude do sistema e na dogmática jurídica dá azo ao surgimento de novas propostas teóricas que se voltam para a práxis do direito, ao invés de retornar ao jusnaturalismo. Neste contexto, surgem as primeiras teorias da argumentação jurídica.

O emprego da palavra "teoria" normalmente está ligado ao sentido de oposição à prática. Porém, nesta conjuntura, aparece num sentido bem diverso. Invariavelmente, toda teoria da argumentação jurídica "revela uma indisfarçável preocupação com a prática, em especial com a aplicação judicial ou administrativa do direito e com a correção racional dos argumentos empregados no discurso de justificação dessas decisões jurídicas"15.

A crença do homem moderno no "seu rigoroso cientificismo, fechou-se para dentro de si, tornando-se incapaz de processar raciocínios com base no senso comum"16, colocou-o sob o dogma da impossibilidade de articulação de argumentos valorativos de forma racional, tornando-o crente de que toda e qualquer decisão que dependa de valoração é arbitrária e desprovida de justificação racional.

Em face da crença ceticista ao uso prático da razão, instaurada pelo método cartesiano e ratificada pela concepção positivista de Kelsen, constitui "a um só tempo, o ponto de arranque e o paradigma a ser combatido por uma teoria da argumentação jurídica"17.

${ }^{14}$ BARROSO, Luís Roberto. Interpretação e aplicação da constituição. p. 314.

15 BUSTAMANTE, Thomas da Rosa de; MAIA, Antonio Cavalvanti. Argumentação como justificação: Em busca de uma definição comum para as Teorias da Argumentação Jurídica contemporâneas. In: BUSTAMANTE, Thomas da Rosa de (Coord.). Teoria do direito e decisão racional: Temas de teoria da argumentação jurídica. Rio de Janeiro: Renovar, 2008. p. 357.

16 BUSTAMANTE, Thomas da Rosa de. Tópica e argumentação jurídica. In: Revista de informação legislativa, v. 41, n. 163, p. 153-165, jul./set. 2004. Disponível em http://www2.senado.leg.br/bdsf/item/id/985. Acesso em 13/02/2016.

17 BUSTAMANTE, Thomas da Rosa de; MAIA, Antonio Cavalvanti. Argumentação como justificação: Em busca de uma definição comum para as Teorias da Argumentação Jurídica contemporâneas. In: BUSTAMANTE, Thomas da Rosa de (Coord.). Teoria do direito e decisão racional: Temas de teoria da argumentação jurídica. Rio de 
GRANADO, Emerson Rodrigo Araújo. ZANON JUNIOR, Orlando Luiz. SANTOS, Rafael Padilha dos. A argumentação jurídica como instrumento de articulação das razões de justificação da decisão judicial. Revista Eletrônica Direito e Política, Programa de Pós-Graduação Stricto Sensu em Ciência Jurídica da UNIVALI, Itajaí, v.11, n.1, 10 quadrimestre de 2016. Disponível em: www.univali.br/direitoepolitica - ISSN 1980-7791.

Theodor Viehweg, no livro Tópica e jurisprudência, cuja primeira edição é datada de 1953, surge como um dos precursores teóricos da argumentação jurídica, rompendo com o dualismo paradigmático do jusnaturalismo e do positivismo jurídico, até então pródigo em construção teórica, mas incapaz de responder aos anseios da prática jurídica.

Referido autor redireciona o debate da jurisprudência - que é entendida como sinônimo de dogmática jurídica, - para a retórica aristotélica, bem como restaura o conceito de razão prática, até então jogada ao esquecimento pelos positivistas ${ }^{18}$.

À luz do pensamento de Viehweg, Ferraz Jr. leciona que argumentação jurídica é uma forma típica de raciocínio, portanto, "raciocinar, juridicamente, é uma forma de argumentar", por sua vez, "argumentar significa, em sentido lato, fornecer motivos e razões dentro de uma forma específica"19.

Assim, a "decisão jurídica aparece [...] como uma discussão racional, isto é, como um operar racional do discurso, cujo terreno imediato é um problema ou um conjunto deles". Portanto, "o pensamento jurídico de onde emerge a decisão deve ser, assim, entendido basicamente como ‘discussão de problemas'”, orienta Ferraz Jr. ${ }^{20}$.

Desta forma, a decisão judicial, que para os positivistas emergiria de uma lógica formal, apoiada em razões de fundamentação sistematizada, surge agora no pensamento de Viehweg da "discussão de problemas", fazendo ressurgir a discussão axiológica na atividade decisória.

Por isso, como aponta Bustamante, Viehweg resgata a "tópica aristotélica, que faz parte do Organon e situa-se no terreno do dialético, e portanto distante do apodítico"21.

Janeiro: Renovar, 2008. p. 358.

18 BUSTAMANTE, Thomas da Rosa de. Tópica e argumentação jurídica.In: Revista de informação legislativa, v. 41, n. 163, p. 153-165, jul./set. 2004. Disponível em http://www2.senado.leg.br/bdsf/item/id/985. Acesso em 13/02/2016.

19 JR. FERRAZ, Tercio Sampaio. Introdução ao Estudo do Direito: Técnica, Decisão, Dominação. São Paulo: Atlas, 2003. p. 324.

20 JR. FERRAZ, Tercio Sampaio. Introdução ao Estudo do Direito: Técnica, Decisão, Dominação. p.324.

21 BUSTAMANTE, Thomas da Rosa de. Tópica e argumentação jurídica.In: Revista de informação legislativa, v. 41, n. 163, p. 153-165, jul./set. 2004. Disponível em http://www2.senado.leg.br/bdsf/item/id/985. Acesso em 13/02/2016. 
GRANADO, Emerson Rodrigo Araújo. ZANON JUNIOR, Orlando Luiz. SANTOS, Rafael Padilha dos. A argumentação jurídica como instrumento de articulação das razões de justificação da decisão judicial. Revista Eletrônica Direito e Política, Programa de Pós-Graduação Stricto Sensu em Ciência Jurídica da UNIVALI, Itajaí, v.11, n.1, 10 quadrimestre de 2016. Disponível em: www.univali.br/direitoepolitica - ISSN 1980-7791.

Neste sentido, Ferraz Jr. consigna que "as demonstrações da ciência seriam apodíticas em oposição às argumentações retóricas, que seriam dialéticas. Dialético seriam os argumentos que concluem com base em premissas aceitas pela comunidade como parecendo verdadeiras"22.

Destarte, Viehweg acreditava que restaurando o pensamento dialético, estabeleceria "processos comunicativos em que são aduzidos argumentos com base em premissas que possuem uma estrutura tópica", de forma a "controlar a racionalidade das tomadas de posição em relação aos valores", afastando assim, a crença da impossibilidade do uso da razão prática ${ }^{23}$.

Nota-se que Viehweg se opõe ao pensamento sistemático do positivismo, haja vista que, enquanto a tópica busca soluções a posteriori aos fatos, aquele se reproduz num pensamento dedutivo "que deduz do apriorístico sistema de normas jurídicas a aplicação do direito ao concreto"24.

O pensamento de Viehweg abre caminho para a proposta de Chaïm Perelman, que seguindo no mesmo referente teórico, combate o absolutismo da lógica formal e a busca pela verdade que permeaiam a razão positivista.

No "Tratado da Argumentação Jurídica: a nova retórica", Perelman expõe sua oposição ao pensamento marcante da lógica formal, a qual limitava a lógica "ao estudo dos meios de prova utilizados nas ciências matemáticas", fato que resultava na conclusão de que "os raciocínios alheios ao campo puramente formal escapam à lógica e, com isso, também à razão"25.

Para isso, Perelman refuta "a conclusão de que a razão é totalmente incompetente nos

22 JR. FERRAZ, Tercio Sampaio. Introdução ao Estudo do Direito: Técnica, Decisão, Dominação. p.327.

23 BUSTAMANTE, Thomas da Rosa de. Tópica e argumentação jurídica.In: Revista de informação legislativa, v. 41, n. 163, p. 153-165, jul./set. 2004. Disponível em http://www2.senado.leg.br/bdsf/item/id/985. Acesso em 13/02/2016.

${ }^{24}$ BITTAR, Eduardo C. B.; ALMEIRA, Guilherme Assis de. Curso de filosofia do direito. p. 509.

25 PERELMAN, Chaïm; OLBRECHTS-TYTECA, Lucie. Tratado da argumentação: a nova retórica. Trad. Maria Ermantina de Almeida Prado Galvão. São Paulo: Martins Fontes, 2005. p. 2-3. 
GRANADO, Emerson Rodrigo Araújo. ZANON JUNIOR, Orlando Luiz. SANTOS, Rafael Padilha dos. A argumentação jurídica como instrumento de articulação das razões de justificação da decisão judicial. Revista Eletrônica Direito e Política, Programa de Pós-Graduação Stricto Sensu em Ciência Jurídica da UNIVALI, Itajaí, v.11, n.1, 10 quadrimestre de 2016. Disponível em: www.univali.br/direitoepolitica - ISSN 1980-7791.

campos que escapam ao cálculo e de que, onde nem a experiência, nem a dedução lógica podem fornecer-nos a solução de um problema"26.

Como resposta, Perelman encontra em Aristóteles o desenvolvimento de "tipo de raciocínios que este, distinguindo-os, claramente (...) dos raciocínios analíticos ou dedutivos (...), chamou de dialético (dos quais trata na Tópica, na Retórica e nas Refutações sofísticas)"27.

Com efeito, propõe Perelman uma teoria da argumentação jurídica, cujo objeto "é o estudo das técnicas discursivas que permitem provocar ou aumentar a adesão dos espíritos às teses que se Ihes apresentam ao assentimento"28, apresentando-a como a nova retórica.

Enquanto o objeto da retórica antiga era restrito à arte da oratória e direcionado a uma multidão reunida numa praça (auditório), de outro lado, a nova retórica preocupa-se mais com a "estrutura da argumentação, não insistirá, portanto, na maneira pela qual se efetua a comunicação com o auditório"29.

Ponto que merece destaque, é a noção de auditório, pois, como ensina Atienza, "tem um papel predominante e se define como 'o conjunto de todos aqueles em quem o orador quer influir com a sua argumentação'”30.

Oportuno consignar, ainda, que o mito da verdade científica, presente no pensamento de Kelsen, pautado num raciocínio lógico-dedutivo, é abandonado em Perelman, o qual se move no "terreno do simplesmente plausível"31.

Como aponta Atienza, "os argumentos retóricos não estabelecem verdades evidentes, provas demonstrativas, e sim mostram o caráter razoável, plausível, de uma determinada

26 PERELMAN, Chaïm; OLBRECHTS-TYTECA, Lucie. Tratado da argumentação: a nova retórica. p. 3.

27 ATIENZA, Manuel. As razões do direito: teorias da argumentação jurídica. Trad. Maria Cristina Guimarães Cupertino. São Paulo: Landy Editora, 2003. p. 60.

28 PERELMAN, Chaïm; OLBRECHTS-TYTECA, Lucie. Tratado da argumentação: a nova retórica. p. 4.

29 PERELMAN, Chaïm; OLBRECHTS-TYTECA, Lucie. Tratado da argumentação: a nova retórica. p. 6.

${ }^{30}$ ATIENZA, Manuel. As razões do direito: teorias da argumentação jurídica. p. 62.

${ }^{31}$ ATIENZA, Manuel. As razões do direito: teorias da argumentação jurídica. p. 61. 
GRANADO, Emerson Rodrigo Araújo. ZANON JUNIOR, Orlando Luiz. SANTOS, Rafael Padilha dos. A argumentação jurídica como instrumento de articulação das razões de justificação da decisão judicial. Revista Eletrônica Direito e Política, Programa de Pós-Graduação Stricto Sensu em Ciência Jurídica da UNIVALI, Itajaí, v.11, n.1, 10 quadrimestre de 2016. Disponível em: www.univali.br/direitoepolitica - ISSN 1980-7791.

decisão ou opinião"32.

Outro ponto de conflito com a teoria dominante (positivismo) é como Perelman visualizava a argumentação. Para ele, a argumentação era "um processo em que todos os seus elementos interagem constantemente, e nisso ela se distingue [...] da concepção dedutiva e unitária do raciocínio de Descartes"33.

O abandono do mito da verdade e a possibilidade de interação entre os elementos argumentativos, traz à tona argumentos retirados do discurso jurídico por ausência de suposta possibilidade de correção racional dentro do método cartesiano.

Desta forma, Perelman inaugura uma nova dinâmica ao raciocínio jurídico, introduzindo a argumentação como modo de gerar convencimento, encontrando limites apenas na "pura evidência, que dispensa a argumentação, e a imposição arbitrária, que impede a argumentação"34.

Dessarte, as teorias argumentativas de Viehweg e de Perelman, pautadas na tópicaretórica, representam um avanço na tentativa de racionalizar o discurso jurídico além do modelo positivista (unitário), pelo padrão de razoabilidade e aceitabilidade dos argumentos articulados no discurso.

Não obstante, Robert Alexy, fortemente influenciado pela teoria do discurso de Jürgen Habermas, buscou elaborar uma teoria, tanto normativa quanto descritiva, de argumentação jurídica, a qual fosse capaz de racionalmente justificar juízos de valor35.

Todas as teorias até aqui exposta encontram-se no contexto filosófico do séc. XX, pósreviravolta linguística-pragmática, na qual a justificação racional do discurso jurídico desponta como questão crucial para a cientificidade do direito ${ }^{36}$.

\footnotetext{
${ }^{32}$ ATIENZA, Manuel. As razões do direito: teorias da argumentação jurídica. p. 61 .

33 ATIENZA, Manuel. As razões do direito: teorias da argumentação jurídica. $p$. $61 / 62$.

${ }^{34}$ BITTAR, Eduardo C. B.; ALMEIRA, Guilherme Assis de. Curso de filosofia do direito.p. 523.

${ }^{35}$ ATIENZA, Manuel. As razões do direito: teorias da argumentação jurídica. p. 158.

36 TOLEDO, Cláudia. Teoria da Argumentação Jurídica.In: Veredas do Direito, Belo Horizonte, v. 2, n. 3, p. 47-65, jan./jun. 2005. Disponível em http://www.domhelder.edu.br/revista/index.php/veredas/article/view/116/97. Acesso
} 
GRANADO, Emerson Rodrigo Araújo. ZANON JUNIOR, Orlando Luiz. SANTOS, Rafael Padilha dos. A argumentação jurídica como instrumento de articulação das razões de justificação da decisão judicial. Revista Eletrônica Direito e Política, Programa de Pós-Graduação Stricto Sensu em Ciência Jurídica da UNIVALI, Itajaí, v.11, n.1, 10 quadrimestre de 2016. Disponível em: www.univali.br/direitoepolitica - ISSN 1980-7791.

Neste norte, a proposta de Alexy é o oferecimento de regras de argumentação que atinjam, por meio da justificação discursiva, consensos racionais ${ }^{37}$.

Assim, comentando a proposta de Alexy, leciona Bustamante que para o referido autor "um enunciado normativo será correto somente se puder ser o resultado de um procedimento comunicativo capaz de lhe conferir um grau satisfatório de racionalidade"38.

A Teoria da Argumentação Jurídica de Alexy está calcada na Teoria do Discurso Geral Racional, a qual institui regras de fundamentação, razão e transição, dentre outras, assegurando, assim, a racionalidade do discurso.

As regras de fundamentação, segundo Bustamante, "são que constituem as condições prévias da possibilidade de comunicação linguística em que se trate de verdade ou correção"39.

Já as regras da razão são normativas e decorrentes da regra geral de fundamentação, as quais Alexy caracteriza na seguinte forma: "Todo falante deve, se lhe é pedido, fundamentar o que afirma, a não ser que possa dar razões que justifiquem negar uma fundamentação"40.

Sem qualquer compromisso com a exaustão da teoria, cabe referir também as regras de transição, as quais decorrem "do fato de que no discurso prático, surgem problemas que obrigam a recorrer a outros tipos de discurso" 41 , a exemplo dos discursos teórico, de análise da linguagem e da própria teoria do discurso.

em 13/02/2016.

37 TOLEDO, Cláudia. Teoria da Argumentação Jurídica.In: Veredas do Direito, Belo Horizonte, v. 2, n. 3, p. 47-65, jan./jun. 2005. Disponível em http://www.domhelder.edu.br/revista/index.php/veredas/article/view/116/97. Acesso em 13/02/2016.

38 BUSTAMANTE, Thomas da Rosa de. Argumentação contra legem: A teoria do discurso e a justificação jurídica nos casos mais difíceis. Rio Janeiro: Renovar, 2005. p. 68.

39 BUSTAMANTE, Thomas da Rosa de. Argumentação contra legem: A teoria do discurso e a justificação jurídica nos casos mais difíceis. p. 79

40 ALEXY, Robert. Teoria da argumentação jurídica: a teoria do discurso racional como teoria da justificação jurídica. Trad. Zilda HutchinsonSchild Silva. Rio de Janeiro: Forense, 2005.

${ }^{41}$ ATIENZA, Manuel. As razões do direito: teorias da argumentação jurídica. p. 169. 
GRANADO, Emerson Rodrigo Araújo. ZANON JUNIOR, Orlando Luiz. SANTOS, Rafael Padilha dos. A argumentação jurídica como instrumento de articulação das razões de justificação da decisão judicial. Revista Eletrônica Direito e Política, Programa de Pós-Graduação Stricto Sensu em Ciência Jurídica da UNIVALI, Itajaí, v.11, n.1, 10 quadrimestre de 2016. Disponível em: www.univali.br/direitoepolitica - ISSN 1980-7791.

Assim, na visão de Alexy, percorrendo o procedimento argumentativo, é assegurada a racionalidade do discurso.

De toda sorte, importa ressaltar que, independente do referente teórico adotado, toda teoria da argumentação jurídica tem um traço comum: onde, em que medida e como podem as necessárias valorações judiciais serem racionalmente justificadas ${ }^{42}$.

Por fim, adotando uma categoria comum às diversas propostas teóricas para a teoria da argumentação jurídica, cita-se a delineada por Bustamante e Maia, no sentido de que "são teorias sobre o emprego dos argumentos e o valor de cada um deles nos discursos de justificação de uma decisão jurídica, visando a um incremento de racionalidade na fundamentação e aplicação prática do direito, na máxima medida possível”33.

\section{O CARÁTER PRESCRITIVO DA CIÊNCIA JURÍDICA E A CONTRIBUIÇÃO DA ARGUMENTAÇÃO JURÍDICA NO SEU DESENVOLVIMENTO}

A compreensão da construção do pensamento científico se perfaz pela análise histórica evolutiva da ciência.

Como aponta Zanon Jr, pautado no pensamento de Thomas S. Kuhn, a formação do conhecimento cientifico não se fixou de forma gradual e progressivamente, mas por meio de "sucessivas revoluções, através das quais a comunidade de estudiosos adota um novo Paradigma (matriz disciplinar ou base teórica) que não está sujeito à crise instalada no modelo anterior"44.

A análise da estrutura das revoluções científicas descritas por Kuhn, passa, necessariamente, pela fixação de três conceitos operacionais, quais sejam: comunidade

42 BUSTAMANTE, Thomas da Rosa de; MAIA, AntonioCavalvanti. Argumentação como justificação: Em busca de uma definição comum para as Teorias da Argumentação Jurídica contemporâneas. In: BUSTAMANTE, Thomas da Rosa de (Coord.). Teoria do direito e decisão racional: Temas de teoria da argumentação jurídica. Rio de Janeiro: Renovar, 2008. p. 362.

43 BUSTAMANTE, Thomas da Rosa de; MAIA, AntonioCavalvanti. Argumentação como justificação: Em busca de uma definição comum para as Teorias da Argumentação Jurídica contemporâneas. In: BUSTAMANTE, Thomas da Rosa de (Coord.). Teoria do direito e decisão racional: Temas de teoria da argumentação jurídica. Rio de Janeiro: Renovar, 2008. p. 363.

${ }^{44}$ ZANON JR., Orlando Luiz. Teoria complexa do direito. p. 40. 
GRANADO, Emerson Rodrigo Araújo. ZANON JUNIOR, Orlando Luiz. SANTOS, Rafael Padilha dos. A argumentação jurídica como instrumento de articulação das razões de justificação da decisão judicial. Revista Eletrônica Direito e Política, Programa de Pós-Graduação Stricto Sensu em Ciência Jurídica da UNIVALI, Itajaí, v.11, n.1, 10 quadrimestre de 2016. Disponível em: www.univali.br/direitoepolitica - ISSN 1980-7791.

científica, entendida como grupo de pessoas que compartilham conhecimento de uma especialidade da ciência; paradigma, consistente na adoção de uma base teórica ou matriz disciplinar compartilhada pela comunidade científica por determinado tempo; e, revolução, entendida como o movimento de superação da matriz teórica de uma comunidade científica ${ }^{45}$.

Neste desiderato, a revolução científica se inicia com a crise da ciência, momento no qual a plataforma teórica não atende mais aos anseios da comunidade científica, por insuficiência ou incorreção, de modo a reclamar a formulação de uma nova proposta teórica, capaz de corrigir e reger a ciência nos problemas vindouros ${ }^{46}$.

Oportuno consignar, que a base teórica de regência da ciência pode ser compreendida sob duas visões distintas, mas complementares. Primeiro, sob o aspecto descritivo, que objetiva descrever "um padrão da leitura da realidade empírica" 47 , e, segundo, sob o aspecto prescritivo, que visa, após avaliação do contexto descritivo, realizar formulações sobre ele.

Contextualizando o exposto na ciência jurídica, o positivismo jurídico surge da crise instaurada na plataforma teórica presente até meados do séc. XIX (jusnaturalismo), na pretensão, principalmente, de diminuir a discricionariedade do aplicador do direito, o qual estava firmado sob a concepção da existência um direito superior, retirado da natureza ou de um plano metafísico, que não respondia mais aos anseios da comunidade científica.

Somando a isso, tem-se os movimentos racionalistas, fortemente influenciados pelo método científico de Descartes, que eram descrentes da cientificidade do direito.

Sob esta realidade, como resposta à negação de uma ciência jurídica, Kelsen propõe o positivismo normativista, que se fecha para qualquer interferência externa (metafísica, sociologia, moral, justiça etc.), numa pretensão de neutralidade científica, restringindo o direito à exclusiva tarefa de descrever a relação da norma jurídica e as suas possíveis interpretações, ou seja, em total abandono do papel prescritivo da ciência.

\footnotetext{
45 ZANON JR., Orlando Luiz. Teoria complexa do direito.p. 40/41.

46 ZANON JR., Orlando Luiz. Teoria complexa do direito.p. 42/43.

47 ZANON JR., Orlando Luiz. Teoria complexa do direito.p. 45.
} 
GRANADO, Emerson Rodrigo Araújo. ZANON JUNIOR, Orlando Luiz. SANTOS, Rafael Padilha dos. A argumentação jurídica como instrumento de articulação das razões de justificação da decisão judicial. Revista Eletrônica Direito e Política, Programa de Pós-Graduação Stricto Sensu em Ciência Jurídica da UNIVALI, Itajaí, v.11, n.1, 10 quadrimestre de 2016. Disponível em: www.univali.br/direitoepolitica - ISSN 1980-7791.

Assim, desponta na segunda metade do séc. $X X$, como visto, as primeiras teorias da argumentação jurídica, na tentativa de restaurar o caráter prescritivo da ciência jurídica.

Nesse substrato, "rompem-se noções profundamente consolidadas pelo positivismo da época, como a crença da neutralidade cientifica no plano da dogmática jurídica [...] e o [...] não cognitivismo ético e axiológico"48.

O surgimento das teorias da argumentação jurídica inicia uma nova revolução no pensar o direito, provocando, "profunda redefinição das funções da ciência do direito".

É certo que o aparecimento e desenvolvimento das teorias argumentativas, que se voltam para o plano da decisão judicial, inicia um processo de superação do paradigma positivista, que restringia a a função da ciência do direito em apenas explicar e descrever a formação da decisão judicial, posto estar ainda preso na suficiência da norma, sem contribuir para sua justificação.

As teorias argumentativas representam aprimoramento da decisão judicial, pois agora interessa não somente o mecanismo de formação da decisão, mas também como e de que forma devem ser justificadas.

Nestes termos, pondera Atienza que a teoria padrão de argumentação jurídica se situa precisamente "no contexto de justificação dos argumentos, e em geral costuma ter pretensões tanto descritivas quanto prescritivas", tratando-se, assim, de estudos que buscam tanto "mostrar como as decisões jurídicas se justificam de fato e também [...] como deveriam elas ser justificadas" 49 .

Com efeito, resta claro que as teorias da argumentação estão no plano descritivo, mas principalmente, no plano normativo, o qual "apresenta caráter manifestamente prescritivo", conquanto "quase todas elas se apresentam como teorias analítico-

48 BUSTAMANTE, Thomas da Rosa de; MAIA, AntonioCavalvanti. Argumentação como justificação: Em busca de uma definição comum para as Teorias da Argumentação Jurídica contemporâneas. In: BUSTAMANTE, Thomas da Rosa de (Coord.). Teoria do direito e decisão racional: Temas de teoria da argumentação jurídica. Rio de Janeiro: Renovar, 2008. p. 359.

${ }^{49}$ ATIENZA, Manuel. As razões do direito: teorias da argumentação jurídica. p. 22. 
GRANADO, Emerson Rodrigo Araújo. ZANON JUNIOR, Orlando Luiz. SANTOS, Rafael Padilha dos. A argumentação jurídica como instrumento de articulação das razões de justificação da decisão judicial. Revista Eletrônica Direito e Política, Programa de Pós-Graduação Stricto Sensu em Ciência Jurídica da UNIVALI, Itajaí, v.11, n.1, 10 quadrimestre de 2016. Disponível em: www.univali.br/direitoepolitica - ISSN 1980-7791.

normativas dos discursos de justificação das decisões judiciais"50.

Vale anotar que as teorias da argumentação jurídica estão no campo das razões justificadoras e não no seio do contexto de descoberta e explicação. Tal ressalva desponta das margens fronteiriças da argumentação com a hermenêutica jurídica. Enquanto a hermenêutica está no âmbito da racionalidade individual (ainda que decorrente da tradição compartilhada) a argumentação reside no âmbito intersubjetivo ${ }^{51}$.

Atienza explica que "uma coisa é o procedimento mediante o qual se estabelece uma determinada premissa ou conclusão, e outra coisa é o procedimento que consiste em justificar essa premissa ou conclusão"52. Portanto, a argumentação está no campo da justificação das decisões.

Isso não significa dizer que é possível uma análise intersubjetiva sem o apanhado teórico da racionalidade individual (hermenêutico).

Em recente opinião emitida por Atienza para a Revista Eletrônica Consultor Jurídico (CONJUR), esclarece que se deve buscar uma concepção argumentativa do Direito que "não descuida dos elementos 'hermenêuticos', mas que trata de integrá-los com os de caráter técnico-jurídico (esquemas lógicos dos argumentos, natureza e peso dos critérios - cânones - interpretativos, etc)"53.

Enfim, resta claro o importante papel que as teorias da argumentação jurídica desempenham no desenvolvimento do aspecto prescritivo da ciência jurídica. Antes morto na pretensão purista do positivismo jurídico, ressurge como proposta de reaproximação de argumentos interdisciplinares e voltados à prática jurídica.

50 BUSTAMANTE, Thomas da Rosa de; MAIA, Antonio Cavalvanti. Argumentação como justificação: Em busca de uma definição comum para as Teorias da Argumentação Jurídica contemporâneas. In: BUSTAMANTE, Thomas da Rosa de (Coord.). Teoria do direito e decisão racional: Temas de teoria da argumentação jurídica. Rio de Janeiro: Renovar, 2008. p. 360.

51 ZANON JR., Orlando Luiz. Teoria complexa do direito.p. 36.

52 ATIENZA, Manuel. As razões do direito: teorias da argumentação jurídica. p. $21 / 22$.

53 ATIENZA, Manuel. Teorias da argumentação jurídica e a hermenêutica não são incompatíveis. In: Revista Eletrônica Consultor Jurídico (CONJUR). Disponível em: http://www.conjur.com.br/2015-out-08/atienza-argumentacao-juridica-hermeneuticanao-sao-incompativeis. Acesso em: 15/02/2016. 
GRANADO, Emerson Rodrigo Araújo. ZANON JUNIOR, Orlando Luiz. SANTOS, Rafael Padilha dos. A argumentação jurídica como instrumento de articulação das razões de justificação da decisão judicial. Revista Eletrônica Direito e Política, Programa de Pós-Graduação Stricto Sensu em Ciência Jurídica da UNIVALI, Itajaí, v.11, n.1, 10 quadrimestre de 2016. Disponível em: www.univali.br/direitoepolitica - ISSN 1980-7791.

\section{A ARGUMENTAÇÃO JURÍDICA COMO INSTRUMENTO DE ARTICULAÇÃO DAS RAZÕES DE JUSTIFICAÇÃO DA DECISÃO JUDICIAL}

Antes de tecer comentário mais aprofundado, faz-se necessário abrir parênteses para a contextualização da teoria das fontes jurídicas, realizando seu enlace à argumentação jurídica.

A teoria das fontes jurídicas constitui uma das plataformas básicas da teoria jurídica. $\mathrm{A}$ partir do modelo juspositivista, a tese da origem social das fontes do direito galgou forte aderência.

Segundo Ferraz Jr., houve uma "tomada de consciência de que o direito não é essencialmente um dado, mas uma construção elaborada no interior da cultura humana". Por isso, ela ganha robustez no "momento em que a ciência jurídica percebe seu objeto (direito) como um produto cultural e não mais como um dado da natureza ou sagrado"54.

Com a finalidade de racionalizar o fenômeno jurídico, para o cumprimento de ideais de justiça e de segurança, cabe especificar a categorizar as fontes do direito validamente admitidas no discurso jurídico.

O termo fonte guarda certa imprecisão terminológica e ambiguidade, mas a dogmática analítica, "utiliza-se da expressão metafórica fonte para descrever os modos de formação das normas jurídicas, ou seja, sua entrada no sistema do ordenamento jurídico"55.

Com efeito, o que deve ser registrado, é que a "noção formal de fontes do Direito apresenta sempre uma estrutura auto-referencial: apenas atos, fatos, procedimentos ou normas juridicamente institucionalizados é que podem gerar normas jurídicas"56.

54 JR. FERRAZ, Tercio Sampaio. Introdução ao Estudo do Direito: Técnica, Decisão, Dominação. p. 223.

55 JR. FERRAZ, Tercio Sampaio. Introdução ao Estudo do Direito: Técnica, Decisão, Dominação. p. 227.

56 BUSTAMANTE, Thomas da Rosa.O direito e a incerteza de suas fontes: um problema em aberto para a dogmática jurídica contemporânea.In: Revista da Faculdade de Direito da UFMG, Belo Horizonte, Número Especial: Jornadas Jurídicas Brasil-Canadá. p. 299-325, 2013. Disponível

em http://www.direito.ufmg.br/revista/index.php/revista/article/view/P.03042340.2013vJjp300/288. Acesso em 13/02/2016. 
GRANADO, Emerson Rodrigo Araújo. ZANON JUNIOR, Orlando Luiz. SANTOS, Rafael Padilha dos. A argumentação jurídica como instrumento de articulação das razões de justificação da decisão judicial. Revista Eletrônica Direito e Política, Programa de Pós-Graduação Stricto Sensu em Ciência Jurídica da UNIVALI, Itajaí, v.11, n.1, 10 quadrimestre de 2016. Disponível em: www.univali.br/direitoepolitica - ISSN 1980-7791.

Em que pese o grande esforço empreendido pelos positivistas para trazer clareza e certeza às fontes do direito, o que se constata é que as concepções tradicionais não são adequadas para abarcar as variadas modalidades argumentativas que compõem 0 discurso judicial atual, tão pouco demonstram como ocorre esta interação ${ }^{57}$.

A crítica de Ronald Dworkin é oportuna, ao destacar que "o positivismo é um modelo de e para um sistema de regras e que sua noção central de um único teste fundamental para o direito nos força a ignorar os papéis importantes desempenhados pelos padrões que não são regras"58.

Retira-se desta crítica que, no discurso prático, são validamente empregados diversos outros os argumentos além das regras jurídicas ${ }^{59}$.

Diferentemente do que imaginam os juspositivistas clássicos, a atividade decisória não consiste, na realidade, em um simples ato de encaixe da premissa menor na maior. Pelo contrário, trata-se de atividade complexa, a qual exige do juiz um grande e difícil processo de conformação de argumentos juridicamente institucionalizados, inclusive de cunho principiológico, sem olvidar de influxos das diversas áreas do conhecimento, a exemplo da economia, da sociologia etc ${ }^{60}$.

Não há uma separação, senão artificial e de conveniência, entre o direito e a moral. A produção jurídica está constantemente sofrendo influxos da moral, seja no processo de positivação, no que desrespeito a produção legislativa, seja na fase de aplicação. Cabe à ciência jurídica abdicar do purismo e, então, enfrentar esta dificuldade, decorrente da subjetividade das análises sociológicas.

\footnotetext{
57 BUSTAMANTE, Thomas da Rosa.O direito e a incerteza de suas fontes: um problema em aberto para a dogmática jurídica contemporânea.In: Revista da Faculdade de Direito da UFMG, Belo Horizonte, Número Especial: Jornadas Jurídicas Brasil-Canadá. p. 299-325, 2013. Disponível em http://www.direito.ufmg.br/revista/index.php/revista/article/view/P.03042340.2013vJjp300/288. Acesso em 13/02/2016.

58 DWORKIN, Ronald. Levando os direitos a sério. São Paulo: Martins Fontes, 2007. P. 46.

${ }^{59}$ Aqui, cabe o esclarecimento adicional de que as regras jurídicas representam um modelo fictício de norma e, efetivamente, não representam uma fonte jurídica, consoante a Teoria Complexa do Direito.

60 ZANON JR., Orlando Luiz. Teoria complexa do direito.p. 101.
} 
GRANADO, Emerson Rodrigo Araújo. ZANON JUNIOR, Orlando Luiz. SANTOS, Rafael Padilha dos. A argumentação jurídica como instrumento de articulação das razões de justificação da decisão judicial. Revista Eletrônica Direito e Política, Programa de Pós-Graduação Stricto Sensu em Ciência Jurídica da UNIVALI, Itajaí, v.11, n.1, 10 quadrimestre de 2016. Disponível em: www.univali.br/direitoepolitica - ISSN 1980-7791.

Na pós-modernidade, num cenário de complexas relações sociais, marcado pela era da velocidade, não é possível restringir os padrões que influenciam o magistrado a uma razão definitiva de dever ser, caracterizada como uma moldura fechada, que desconsidera os demais critérios de julgamento legitimamente empregados nas diversas atividades humanas.

Ora, "a teoria do Direito não pode simplesmente ignorar que existem outros diversos padrões de julgamento que conformam a produção normativa e que, portanto, merecem ser considerados como frações, legítimas ou ilegítimas, do sistema", consigna Zanon Jr. ${ }^{61}$.

Como aponta Bustamante, "uma teoria jurídica que pretenda ser relevante para a prática", deve ir além do reducionismo positivista, para fixar "os fatores que determinam o peso dos argumentos jurídicos em cada caso concreto", bem como deve estabelecer "critérios para entender qual tipo de argumentos e razões deve contar na justificação de uma decisão jurídica"62.

Desta forma, resta suficientemente justificada a necessidade de uma teoria das fontes do Direito adequada ao pensamento pós-positivista, que não ignore simplesmente fatores de inegável influência no discurso jurídico.

Assim, Aulis Aarnio apud Bustamante, propõe um conceito argumentativo para as fontes do Direito, considerando como "toda razão que - de acordo com as regras geralmente aceitas na comunidade jurídica - pode ser usada como base justificatória da interferência jurídica"63.

Ainda, sob o mesmo viés pós-positivista, sugere Zanon Jr. que "fontes são todos os

61 ZANON JR., Orlando Luiz. Teoria complexa do direito.p. 103.

62 BUSTAMANTE, Thomas da Rosa.O direito e a incerteza de suas fontes: um problema em aberto para a dogmática jurídica contemporânea.In: Revista da Faculdade de Direito da UFMG, Belo Horizonte, Número Especial: Jornadas Jurídicas Brasil-Canadá. p. 299-325, 2013.

Disponível

em http://www.direito.ufmg.br/revista/index.php/revista/article/view/P.03042340.2013vJjp300/288. Acesso em 13/02/2016.

63 BUSTAMANTE, Thomas da Rosa.O direito e a incerteza de suas fontes: um problema em aberto para a dogmática jurídica contemporânea.In: Revista da Faculdade de Direito da UFMG, Belo Horizonte, Número Especial: Jornadas Jurídicas Brasil-Canadá. p. 299-325, 2013. Disponível

em http://www.direito.ufmg.br/revista/index.php/revista/article/view/P.03042340.2013vJjp300/288. Acesso em 13/02/2016. 
GRANADO, Emerson Rodrigo Araújo. ZANON JUNIOR, Orlando Luiz. SANTOS, Rafael Padilha dos. A argumentação jurídica como instrumento de articulação das razões de justificação da decisão judicial. Revista Eletrônica Direito e Política, Programa de Pós-Graduação Stricto Sensu em Ciência Jurídica da UNIVALI, Itajaí, v.11, n.1, 10 quadrimestre de 2016. Disponível em: www.univali.br/direitoepolitica - ISSN 1980-7791.

elementos que podem ser empregados para tomada de decisões e, portanto, o conceito operacional engloba a totalidade do conhecimento já construído ou passível de construção por empreendimento racional"64.

Ambos os conceitos apresentados não fecham as fontes em elementos taxativos, de sorte que convida a argumentação jurídica a desempenhar um importante papel na articulação das razões de justificação da decisão judicial.

Neste ponto, vale resgatarmos o conceito operacional adotado para teoria da argumentação jurídica no final do item 1.

Restou consignado que as teorias da argumentação jurídica versão sobre "o emprego dos argumentos e o valor de cada um deles nos discursos de justificação de uma decisão jurídica, visando a um incremento de racionalidade na fundamentação e aplicação prática do direito, na máxima medida possível"65.

Quando se traz a ideia de instrumento de articulação, destaca-se o importante papel normativo/prescritivo da argumentação jurídica, a qual fechará e restringirá, mediante regras argumentativas, independentemente do referente teórico, a margem decisória.

Afirmar que são teorias sobre o emprego de argumentos, significa dizer que são proposições que se preocupam com a construção racional das razões de decidir, ou seja, preocupam-se em colocar à disposição do intérprete instrumentos que racionalmente justifiquem, segundo regras argumentativas, as valorações jurídicas ${ }^{66}$.

A teoria da argumentação jurídica, ensina Atienza, deve desempenhar três funções, quais sejam, "a primeira é de caráter teórico ou cognoscitivo, a segunda tem uma natureza

${ }^{64}$ ZANON JR., Orlando Luiz. Teoria complexa do direito.p. 159.

65 BUSTAMANTE, Thomas da Rosa de; MAIA, AntonioCavalvanti. Argumentação como justificação: Em busca de uma definição comum para as Teorias da Argumentação Jurídica contemporâneas. In: BUSTAMANTE, Thomas da Rosa de (Coord.). Teoria do direito e decisão racional: Temas de teoria da argumentação jurídica. Rio de Janeiro: Renovar, 2008. p. 363.

66 BUSTAMANTE, Thomas da Rosa de; MAIA, AntonioCavalvanti. Argumentação como justificação: Em busca de uma definição comum para as Teorias da Argumentação Jurídica contemporâneas. In: BUSTAMANTE, Thomas da Rosa de (Coord.). Teoria do direito e decisão racional: Temas de teoria da argumentação jurídica. Rio de Janeiro: Renovar, 2008. p. 362/364. 
GRANADO, Emerson Rodrigo Araújo. ZANON JUNIOR, Orlando Luiz. SANTOS, Rafael Padilha dos. A argumentação jurídica como instrumento de articulação das razões de justificação da decisão judicial. Revista Eletrônica Direito e Política, Programa de Pós-Graduação Stricto Sensu em Ciência Jurídica da UNIVALI, Itajaí, v.11, n.1, 1o quadrimestre de 2016. Disponível em: www.univali.br/direitoepolitica - ISSN 1980-7791.

prática ou técnica e a terceira poderia ser qualificada de política ou moral"67.

No caso, importa analisar apenas a segunda natureza. Entende-se por "função prática ou técnica da argumentação jurídica, [...] basicamente que esta deve ser capaz de oferecer uma orientação útil nas tarefas de produzir, interpretar e aplicar o Direito", para tanto, será necessário fornecer "um método que permita reconstruir o processo real da argumentação, além de uma série de critérios para fazer um julgamento sobre a sua correção"68.

Portanto, através de um estabelecimento de um método argumentativo, resta viável a construção de instrumentos válidos de articulação das razões de justificativa na decisão judicial.

Em suma, as fronteiras que separavam o Direito de influxos externos não passam de uma articulação de conveniência, de forma que a teoria das fontes do Direito adequada deve considerar, além dos argumentos institucionalizados, também aquelas demais que realmente interferem na formação do discurso prático.

\section{CONSIDERAÇÕES FINAIS}

A teoria da argumentação jurídica está em grande evidência no cenário jurídico mundial.

Há uma constatação corrente de que o positivismo jurídico, como modelo paradigmático da ciência jurídica, não oferece mais respostas satisfatórias aos problemas com os quais o operador do direito se depara diariamente.

A barreira artificial construída pelo positivismo normativista, para separar o direito de influxos externos (justiça, moral, ética), tratou de um projeto fracassado, em seus aspectos descrito e prescritivo.

Ignorar que existem outros argumentos jurídicos que podem validamente ser utilizados na construção da decisão judicial não assegurará a cientificidade do direito, apenas criará

67 ATIENZA, Manuel. As razões do direito: teorias da argumentação jurídica. p. 224. 68 ATIENZA, Manuel. As razões do direito: teorias da argumentação jurídica. $p$. $224 / 225$. 
GRANADO, Emerson Rodrigo Araújo. ZANON JUNIOR, Orlando Luiz. SANTOS, Rafael Padilha dos. A argumentação jurídica como instrumento de articulação das razões de justificação da decisão judicial. Revista Eletrônica Direito e Política, Programa de Pós-Graduação Stricto Sensu em Ciência Jurídica da UNIVALI, Itajaí, v.11, n.1, 1o quadrimestre de 2016. Disponível em: www.univali.br/direitoepolitica - ISSN 1980-7791.

um ambiente fictício, sem correspondência com a realidade.

A teoria da argumentação jurídica parte da possibilidade de pensar o direito de forma diferente da lógica formal de subsunção, seja por meio do resgate da retórica aristotélica, seja através das teorias argumentativa-discursivas, sem que se perca a racionalidade do discurso jurídico.

A admissão de novos argumentos no discurso jurídico impõe a reformulação da teoria das fontes jurídicas.

Desta forma, uma teoria das fontes deveria admitir toda razão juridicamente aceita pela comunidade científica, mediante a observância de um procedimento argumentativo previamente fixado.

Nesse passo, a teoria da argumentação jurídica pode ser aceita como instrumento de articulação das razões justificadoras da decisão judicial.

\section{REFERÊNCIA DAS FONTES CITADAS}

ALEXY, Robert. Teoria da argumentação jurídica: a teoria do discurso racional como teoria da justificação jurídica. Trad. Zilda HutchinsonSchild Silva. Rio de Janeiro: Forense, 2005.

ATIENZA, Manuel. As razões do direito: teorias da argumentação jurídica. Trad. Maria Cristina Guimarães Cupertino. São Paulo: Landy Editora, 2003.

ATIENZA, Manuel. Teorias da argumentação jurídica e a hermenêutica não são incompatíveis. In: Revista Eletrônica Consultor Jurídico (CONJUR). Disponível em: http://www.conjur.com.br/2015-out-08/atienza-argumentacao-juridica-hermeneutica-naosao-incompativeis. Acesso em: 15/02/2016.

BARROSO, Luís Roberto. Interpretação e aplicação da constituição. São Paulo: Saraiva, 2004.

BITTAR, Eduardo C. B.; ALMEIRA, Guilherme Assis de. Curso de filosofia do direito. 
GRANADO, Emerson Rodrigo Araújo. ZANON JUNIOR, Orlando Luiz. SANTOS, Rafael Padilha dos. A argumentação jurídica como instrumento de articulação das razões de justificação da decisão judicial. Revista Eletrônica Direito e Política, Programa de Pós-Graduação Stricto Sensu em Ciência Jurídica da UNIVALI, Itajaí, v.11, n.1, 1o quadrimestre de 2016. Disponível em: www.univali.br/direitoepolitica - ISSN 1980-7791.

São Paulo: Atlas, 2015.

BUSTAMANTE, Thomas da Rosa de. Tópica e argumentação jurídica. In: Revista de informação legislativa, v. 41, n. 163, p. 153-165, jul./set. 2004. Disponível em http://www2.senado.leg.br/bdsf/item/id/985. Acesso em 13/02/2016.

BUSTAMANTE, Thomas da Rosa de; MAIA, Antonio Cavalvanti. Argumentação como justificação: Em busca de uma definição comum para as Teorias da Argumentação Jurídica contemporâneas. In: BUSTAMANTE, Thomas da Rosa de (Coord.). Teoria do direito e decisão racional: Temas de teoria da argumentação jurídica. Rio de Janeiro: Renovar, 2008.

BUSTAMANTE, Thomas da Rosa de. Argumentação contra legem: A teoria do discurso e a justificação jurídica nos casos mais difíceis. Rio Janeiro: Renovar, 2005.

BUSTAMANTE, Thomas da Rosa. O direito e a incerteza de suas fontes: um problema em aberto para a dogmática jurídica contemporânea.In: Revista da Faculdade de Direito da UFMG, Belo Horizonte, Número Especial: Jornadas Jurídicas Brasil-Canadá. p. 299325, $2013 . \quad$ Disponível em http://www.direito.ufmg.br/revista/index.php/revista/article/view/P.03042340.2013vJJp300/288. Acesso em 13/02/2016.

DIMOULIS, Dimitri. Positivismo jurídico: Introdução a uma teoria do direito e defesa do pragmatismo jurídico-político. São Paulo: Método, 2006.

DWORKIN, Ronald. Levando os direitos a sério. São Paulo: Martins Fontes, 2007. P. 46.

FERNÁNDEZ, Eusebio. ASÍS, Rafael de. Curso de teoria delderecho. Madrid: Marcial Pons, 2000.

JR. FERRAZ, Tercio Sampaio. Introdução ao Estudo do Direito: Técnica, Decisão, Dominação. São Paulo: Atlas, 2003. 
GRANADO, Emerson Rodrigo Araújo. ZANON JUNIOR, Orlando Luiz. SANTOS, Rafael Padilha dos. A argumentação jurídica como instrumento de articulação das razões de justificação da decisão judicial. Revista Eletrônica Direito e Política, Programa de Pós-Graduação Stricto Sensu em Ciência Jurídica da UNIVALI, Itajaí, v.11, n.1, 1o quadrimestre de 2016. Disponível em: www.univali.br/direitoepolitica - ISSN 1980-7791.

KELSEN, Hans. Teoria pura do direito. Trad. João Baptista Machado. Coimbra: Arménio Amado. 1976.

PERELMAN, Chaïm; OLBRECHTS-TYTECA, Lucie. Tratado da argumentação: a nova retórica. Trad. Maria Ermantina de Almeida Prado Galvão. São Paulo: Martins Fontes, 2005.

PASOLD, Cesar Luis. Metodologia da pesquisa jurídica: Teoria e prática. 11 ed. Florianópolis: Conceito editorial/Milleniuum, 2008.

TOLEDO, Cláudia. Teoria da Argumentação Jurídica.In: Veredas do Direito, Belo Horizonte, v. 2, n. 3, p. 47-65, jan./jun. 2005. Disponível em http://www.domhelder.edu.br/revista/index.php/veredas/article/view/116/97. Acesso em 13/02/2016.

ZANON JR., Orlando Luiz. Teoria complexa do direito. Curitiba: Editora Prismas, 2015.

Submetido em: novembro de 2015.

Aprovado em: Março de 2016. 